\title{
PERCEPÇÃo de PROFessores de ENSino MÉdio ACERCA DA UTILIZAÇÃO DO COMPUTADOR NA ESCOLA: UMA REALIDADE DO SERTÃo PERNAMBUCANO
}

\author{
PERCEPTION OF HIGH SCHOOL TEACHERS ABOUT THE USE OF \\ COMPUTERS IN SCHOOL: A REALITY OF PERNAMBUCO SERTÃO
}

DOI: http://dx.doi.org/10.23926/RPD.2526-2149.2019.v4.n2.p728-743.id406

\author{
Maria Emília Ferraz \\ Almeida de Melo \\ Doutora em Educação \\ (UFRGS) \\ Professora na Universidade \\ de Pernambuco (UPE) \\ emilia.ferraz@upe.br \\ Cristhiane Maria \\ Bazílio de Omena \\ Doutora em Ciências \\ (UFAL) \\ Professora na Universidade \\ de Pernambuco (UPE) \\ cristhiane.omena@upe.br
}

\section{Félix Alexandre}

Antunes Soares

Doutor em Ciências

Biológicas (UFRGS)

Professor Associado na

Universidade Federal de

Santa Maria (UFSM)

felix@ufsm.br
Resumo: Apesar da importância do uso de tecnologias nas escolas, são escassas as investigações acerca destas no ensino, principalmente as que investigam a ótica dos professores acerca desse processo. Pensando nisso, este estudo investigou a utilização do computador no espaço escolar por professores de escolas públicas estaduais, bem como suas percepções acerca das potencialidades e dificuldades no uso dessa ferramenta. Foi realizado um estudo qualitativo, descritivo e intencional com professores do terceiro ano do Ensino Médio, que preencheram um questionário com questões sobre sua formação e algumas experiências e opiniões a respeito do uso do computador para fins didáticos. Foi observado que a maioria dos professores usa o computador em sua prática docente, apesar das extensas jornadas de trabalho. No entanto, acham este recurso limitado para abordar os conteúdos de suas disciplinas e admitem que deveriam explorar melhor os laboratórios de informática da escola. A partir desses resultados, percebe-se que é imprescindível discutir melhor o uso do computador nas escolas, investigando aspectos que melhorem a segurança do professor nesse processo.

Palavras-chave: Computador; Ensino Médio; Prática Docente

\begin{abstract}
Despite the importance of the technologies use at schools, there are few researches about them in education, especially those that investigate the teachers' perspective on this process. Thinking about this, this study investigated the computer use by state public school teachers, as well as their perceptions about the potentialities and difficulties in using this tool. A qualitative, descriptive and intentional study was carried out with teachers from the third year of high school, who filled out a quiz with questions about their training and some experiences and opinions regarding computer use for teaching purposes. It has been observed that most teachers use the computer in their teaching practice, despite extensive working hours. However, they find this resource limited to address the content of their subjects and admit that they should better explore the school's computer labs. From these results, it is necessary to discuss better the use of computers in schools, investigating aspects that improve teacher safety in this process.
\end{abstract}

Keywords: Computer; High School; Teaching Practice. 


\section{INTRODUÇÃO}

Cada vez mais a sociedade atual é influenciada pelos meios de comunicação. Dessa forma, o meio educacional também tende a acompanhar essas mudanças. Apesar dos conflitos gerados nesse processo, devido às competências exigidas para trabalhar com essas ferramentas, é consenso a importância das tecnologias nas instituições escolares. No entanto, a forma como essa introdução ocorre ainda é alvo de discussões (ROCHA, 2011).

Este é um grande debate público e político sobre educação, principalmente quando o objetivo é gerar mudanças no exercício de ensino. Dentre os dilemas aos quais os sistemas educacionais são confrontados, frente à incorporação dessas tecnologias, está a questão das oportunidades que essa ferramenta oferece em relação à aprendizagem, à gestão e à formação de professores (ORTEGA, 2014).

A valorização do uso do computador e das redes de comunicação vêm transformando a sociedade contemporânea numa teia global de pessoas, compartilhando conhecimento e informações. No entanto, é necessário planejar o ambiente de ensino da forma mais adequada, fazendo com que o aluno identifique problemas, busque as informações necessárias para a solução, filtre esses resultados, tire conclusões convincentes, e, por fim, transmita suas conclusões a terceiros. Para isso, o professor pode ser um grande facilitador, no entanto, a introdução dessas novas tecnologias vêm se tornando um grande complicador, acrescentando mais trabalho e estudo à tão pesada carga de atribuições que os docentes já possuem (BARBOSA, 2002).

Os professores são protagonistas desse processo, estão imersos em diversas demandas por mudança, portanto, deve-se conhecer melhor as condições que podem fortalecer ou enfraquecer essas transformações (ORTEGA, 2014). Sabe-se que os alunos que nasceram nessa era digital não têm dificuldades com aparelhos como: computadores, tablets, smartphones e celulares. Estes podem ser meios importantes para o aprendizado, porém, muitas escolas também não estão equipadas de forma suficiente para atender esta necessidade social (OLIVEIRA et al., 2017).

Nesse sentido, ainda são escassos, na literatura atual, estudos mais aprofundados a respeito dos reais obstáculos à inserção das TIC nas escolas, principalmente no que tange a uma abordagem da percepção dos sujeitos envolvidos nessa ação. Muitas vezes, é atribuída aos professores a responsabilidade de promover situações de ensino mediadas por tecnologias digitais, quando não foram preparados para essa diversidade de práticas na sua formação inicial. Isso resulta em modelos distorcidos e incoerentes ao que é, atualmente, desejado (OLIVEIRA 
et al., 2017). Para isso, é preciso conhecer melhor a percepção dos professores nesse processo, a fim de identificar as possíveis razões para o insucesso da utilização desses recursos em suas práticas pedagógicas.

Assim, o presente artigo buscou apresentar as principais utilizações do computador no espaço escolar por professores do último ano do Ensino Médio de escolas públicas estaduais, analisando também suas percepções acerca das potencialidades e dificuldades no uso dessa ferramenta.

\section{REFERENCIAL TEÓRICO}

As escolas e seus profissionais têm vivenciado, ao longo dos anos, a inserção das tecnologias na sua prática cotidiana, implicando numa grande adaptação do seu processo de trabalho (ROCHA, 2011). No Brasil, o uso das tecnologias de informação e comunicação (TIC) na educação ganhou destaque a partir de 1990, quando foram criadas as primeiras políticas públicas que visavam o acesso ao computador e à internet nas escolas. Posteriormente, foram implementados programas voltados à produção de conteúdos digitais, bem como à distribuição dessas ferramentas num modelo 1:1 (um equipamento por estudante) nas escolas, denominado programa Um Computador por Aluno (UCA) (CETIC.BR, 2016).

Embora as necessidades de cobertura tecnológica estejam parcialmente contempladas nas diversas instituições escolares, ainda existem problemas associados à adoção de competências digitais por professores e alunos, bem como aquisição de competências pedagógicas, por parte dos docentes, que lhes permitam criar metodologias adequadas ao uso dessa ferramenta em suas práticas de ensino (ARANCIBIA HERRERA; CASANOVA SEGUEL; SOTO CARO, 2016). É preciso avaliar as concepções de ensino através das TIC, e refletir sobre sua importância no processo ensino-aprendizagem e não apenas informatizar as metodologias usadas tradicionalmente nas escolas (SILVA; HOFF, 2015).

São muitos os recursos tecnológicos que podem ser empregados em sala de aula, entretanto, é preciso que o professor tenha o seu planejamento pedagógico atrelado ao uso dessas tecnologias conforme o seu interesse e a sua disponibilidade (COLETTO; BATTINI; MONTEIRO, 2018). Para isso, um fator importante é a formação inicial e continuada dos docentes, para que possam acompanhar todas as mudanças que envolvem o ambiente escolar, uma vez que existe um distanciamento entre o que é trabalhado nas licenciaturas e o que é de fato desenvolvido durante a atividade docente. $\mathrm{O}$ ensino de ideias pedagógicas durante a sua formação inicial afeta o perfil do professor, no modo particular para o uso das TICs (SILVA; 
NETO; AZEVEDO, 2018; ARANCIBIA HERRERA; CASANOVA SEGUEL; SOTO CARO, 2016).

Outro estudo, a respeito do uso das tecnologias pelos professores, aponta que até o contexto familiar, pela presença de parentes próximos que dominam o uso das TIC e que oferecem assistência permanente para sanar dúvidas, bem como o campo pessoal, quando o professor aproveita o caráter lúdico que as TICs possuem, como diversão no tempo livre, jogos e acesso às redes de comunicação on-line, são fatores que facilitam o emprego deste recurso nos processos de ensino-aprendizagem. Por outro lado, o medo relatado pelos docentes de que possam ser superados pelos alunos, por terem menos conhecimento e habilidade, bem como a preocupação de que possam ser substituídos pelo uso dessas ferramentas, acabam por inibir o seu uso no ambiente escolar (ORTEGA, 2014).

A infraestrutura da escola para o uso das TICs também vem sendo apontada como uma justificativa para a dificuldade do professor em inserir essa ferramenta nas suas práticas pedagógicas, uma vez que nem sempre há oferta de recursos em quantidade suficiente para atender a todos os alunos e professores, nem atualização periódica destes recursos, tampouco profissionais suficientes para dar suporte ao professor durante o uso dessas ferramentas durante as aulas (ROCHA, 2011; BITANTE et al., 2016; SCHUHMACHER; ALVES FILHO; SCHUHMACHER, 2017).

É preciso, então, pensar o atual papel do professor de modo amplo, não só em relação ao seu papel de facilitador do processo de pedagógico, mas em relação ao currículo e ao contexto da escola (ROCHA, 2011). As barreiras que emergiram com o uso das TIC no processo ensino-aprendizagem devem ser consideradas como uma nova linha de investigação no campo da educação, uma vez que permitirá a produção de conhecimentos e avanços nessas novas concepções didáticas (SCHUHMACHER; ALVES FILHO; SCHUHMACHER, 2017).

Para isso, investigações acerca da percepção de professores sobre o uso das tecnologias educacionais trazem indicadores importantes sobre: formação de professores, espaços escolares a serem utilizados para este fim, bem como formas de utilização das TICs nas aulas propriamente ditas. Conforme alguns dados já publicados, os professores acreditam no potencial das TICs para tornar as aulas mais atrativas e melhorar o aprendizado dos alunos, porém sentem-se despreparados para os uso desses recursos (ANJOS; OLIVEIRA; CAIXETA, 2014; BITANTE et al., 2016; NISHI; SILINSKE; LÖBLER, 2017).

Além disso, ainda não estão claros os principais usos do computador pelos professores, suas principais dificuldades e as suas opiniões a respeito da relação deste uso com o 
desempenho escolar dos alunos. Sendo assim, o objetivo do presente estudo foi investigar as principais utilizações do computador no espaço escolar por professores do último ano do Ensino Médio de escolas públicas estaduais, analisando também suas percepções acerca das potencialidades e dificuldades no uso dessa ferramenta.

\section{Metodologia}

Foi realizado um estudo qualitativo, descritivo, de corte transversal, com professores do terceiro ano do Ensino Médio de quatro escolas públicas estaduais localizadas na cidade de Petrolina-PE. Por acreditar que as escolas de área urbana seriam mais acessíveis e melhor estruturadas, no que se refere à existência de laboratórios de informática e oferta de rede de internet, optou-se por realizar a coleta apenas na área urbana. Foram selecionadas as escolas no entorno da Universidade de Pernambuco (UPE) por pensar em intervenções futuras da academia nestas unidades, através de projetos de pesquisa e extensão, baseados nos resultados da presente pesquisa. Também foi escolhida a Escola de Aplicação da UPE (Professora Vande de Souza Ferreira) para realização do estudo piloto e testagem do instrumento de coleta utilizado nesta pesquisa.

Foram selecionadas intencionalmente quatro escolas que oferecem Ensino Médio regular, sendo estas: Escola Dom Malan, Escola Gercino Coelho, Escola Professora Adelina Almeida e Escola de Aplicação Professora Vande de Souza Ferreira. A pesquisa se deu entre fevereiro e maio de 2018 e seguiu as diretrizes e normas que regulamentam as pesquisas envolvendo seres humanos, contidos na resolução 466/2012, sendo aprovado pelo comitê de ética em pesquisa da Universidade de Pernambuco, sob o parecer $\mathrm{n}^{\circ} 1.529 .372$ de maio de 2016 .

A amostra foi intencional, onde todos os professores do terceiro ano do Ensino Médio das referidas escolas foram convidados a participar da pesquisa como voluntários, preenchendo um questionário de autopreenchimento com perguntas estruturadas, baseado nos estudos de Anjos, Oliveira e Caixeta (2014) e a partir da literatura estudada e dos objetivos da pesquisa. O instrumento de coleta continha informações sobre o perfil dos docentes no que se refere à idade, formação profissional, condições de trabalho, acesso à internet, principais utilizações do computador e da internet, bem como suas opiniões a respeito do uso do computador para fins didáticos.

Para investigação dessa opinião, foram elaboradas afirmativas sobre o assunto, no formato de uma Escala de Likert, onde o docente escolheu entre as opções: discordo totalmente, discordo parcialmente, nem concordo nem discordo, concordo parcialmente ou concordo 
totalmente. Com as afirmativas, buscou-se obter a opinião dos docentes a respeito da formação e capacitação necessárias para o uso do computador com fins didáticos, a relação do uso dessa ferramenta com a melhoria da aprendizagem, motivação e rendimento dos alunos, sua relação com a evasão escolar, bem como as possíveis aplicações deste recurso nas disciplinas ministradas pelos professores abordados. As respostas obtidas foram categorizadas e analisadas através de estatística descritiva e análises de relação entre algumas variáveis pessoais e profissionais dos sujeitos e o uso do computador na escola.

Para a análise dos dados foram utilizados os programas Excell 2013® para compilação dos dados e elaboração de tabelas e gráficos, para melhor visualização dos resultados. Em caso de lacunas no preenchimento de alguns questionários, estes sujeitos foram excluídos da análise de algumas variáveis, porém sem comprometer a validade dos dados.

\section{Resultados}

Foram incluídos no estudo 17 professores, sendo 7 mulheres (41\%) e 10 homens (59\%), com média de idade de 35 anos $( \pm 7,3)$, que lecionavam nas diversas disciplinas do Ensino Médio. O tempo médio de magistério dos participantes foi de nove anos $( \pm 6,3)$ e as suas principais características quanto ao perfil profissional encontram-se expostas na Tabela 1.

Percebe-se que a maioria dos docentes tem formação de graduação ou especialização, mostrando um baixo número de professores que chegam à formação Stricto Sensu. Predominam os docentes que trabalham 40 horas semanais ou mais e que gastam entre seis e dez horas semanais com atividades administrativas. Muitos atuam em até duas disciplinas na escola onde foi abordado para a pesquisa e trabalham em até duas escolas.

Tabela 1 - Características de formação e atuação profissional dos professores incluídos na amostra (Petrolina, 2018)

\begin{tabular}{lcc}
\hline VARIÁ VEL & N & \% \\
\hline Formação & & \\
Ciências Biológicas & 2 & 12 \\
Educação Física & 2 & 12 \\
Física & 2 & 12 \\
Geografia & 1 & 6 \\
História & 1 & 6 \\
Letras Inglês & 2 & 12 \\
Letras Português & 3 & 16 \\
Matemática & 2 & 12 \\
Pedagogia & 1 & 6 \\
Química & 1 & 6 \\
Escolaridade & & \\
Ensino Médio & 1 & 6 \\
Graduação & 7 & 41 \\
\hline
\end{tabular}




\begin{tabular}{lcc}
\hline Especialização & 8 & 47 \\
Mestrado & 1 & 6 \\
Número de escolas que atua & & \\
Uma & 9 & 52 \\
Duas & 8 & 48 \\
Carga horária de aula semanal & 3 & \\
Até 20h & 10 & 18 \\
40h & 4 & 59 \\
41h ou mais & & 23 \\
Carga horária administrativa & 3 & \\
Até 5h & 11 & 18 \\
6 a 10h & 3 & 64 \\
11h ou mais & & 18 \\
Quantas disciplinas leciona & 15 & 88 \\
1 a 2 & 2 & 12 \\
3 ou mais
\end{tabular}

n= número de indivíduos; \%=porcentagem. Fonte: Dados dos autores, 2018.

Ortega (2014) afirma que os processos de mudança pedagógica com o uso de TIC são influenciados por três pontos: o primeiro está relacionado aos diferentes níveis de estudo do professor (se formação básica, Ensino Médio, graduação ou educação continuada ou pósgraduação), quando as TICs aparecem no seu currículo de formação. O segundo está relacionado às demandas de trabalho, quando estas favorecem a permanência no local de trabalho. O terceiro está relacionado ao contexto de motivações diversas, desenvolvidas na esfera pessoal.

Do mesmo modo, um dos aspectos vistos como barreira à implementação das tecnologias em atividades pedagógicas, destacam-se a falta de tempo para praticar, conhecer novas ferramentas ou preparar material para suas aulas, assim como, quando as atividades de treinamento ou formação continuada são incompatíveis com o seu horário de trabalho, limitando sua participação motivação para permanecer nesse processo. Isso chama a atenção aos aspectos de anos e tipo de formação, distribuição da carga horária de trabalho, como fatores que merecem ser considerados no planejamento de inserção das TIC no ambiente escolar (ORTEGA, 2014).

Com relação ao uso do computador no ambiente escolar (Tabela 2), a maior parte dos professores confirma que o uso deste recurso está contemplado no projeto pedagógico da escola (88\%) e que utiliza algum software nas disciplinas ministradas por eles (70\%), mesmo com a aparente falta de incentivo da gestão em utilizar os laboratórios de informática (59\%). As respostas dos professores mostram, ainda, que estes sentem-se preparados para usar o recurso em sala de aula (94\%), mas que esta preparação não se deu no seu curso de graduação (59\%). 
Tabela 2 - Descrição do uso do computador na escola, segundo os professores abordados (Petrolina, 2018)

\begin{tabular}{|c|c|c|}
\hline VARIÁVEIS & $\mathrm{n}$ & $\%$ \\
\hline \multicolumn{3}{|c|}{$\begin{array}{l}\text { O uso do computador está contemplado no projeto } \\
\text { pedagógico da escola? }\end{array}$} \\
\hline Sim & 15 & 88 \\
\hline Não & 2 & 12 \\
\hline \multicolumn{3}{|c|}{ Usa algum software na sua disciplina? } \\
\hline Sim & 12 & 70 \\
\hline Não & 5 & 30 \\
\hline \multicolumn{3}{|c|}{ Sente-se preparado para usar o computador na sala de aula? } \\
\hline Sim & 16 & 94 \\
\hline Não & 1 & 6 \\
\hline \multicolumn{3}{|c|}{ Você foi preparado na sua graduação para o uso do computador em sala de aula? } \\
\hline Sim & 7 & 41 \\
\hline Não & 10 & 59 \\
\hline \multicolumn{3}{|c|}{ A gestão da escola incentiva o uso do laboratório de informática? } \\
\hline Sim & 7 & 41 \\
\hline Não & 9 & 59 \\
\hline \multicolumn{3}{|l|}{ Local de acesso à internet } \\
\hline Casa & 15 & 88 \\
\hline Trabalho & 8 & 47 \\
\hline Rede móvel do telefone & 4 & 23 \\
\hline \multicolumn{3}{|c|}{ Como aprendeu a usar o computador? } \\
\hline Sozinho & 8 & 47 \\
\hline Curso & 9 & 53 \\
\hline
\end{tabular}

n= número de indivíduos; \%=porcentagem. Fonte: Dados dos autores, 2018.

Os professores relatam que aprenderam a usar o computador a partir de cursos específicos (53\%) ou até mesmos sozinhos (47\%). Costumam utilizar a internet, porém a fazem, geralmente, em suas residências ( $88 \%)$. Chama a atenção que o uso da internet no trabalho foi relatado por pouco menos da metade dos professores $(47 \%)$, o que pode sugerir que o computador pode ser subutilizado para fins didáticos no ambiente escolar (Tabela 2).

Tais resultados mostram a necessidade de oferecer aos professores, na graduação ou fora dela, uma capacitação para o uso do computador e das tecnologias no contexto escolar. É importante destacar que o fato de o professor sentir-se "preparado" para o uso das tecnologias em sala de aula implica não só em deter conhecimento sobre computadores, mas apropriar-se de um processo de ensino que crie condições para o aprendizado ativo de conceitos, habilidades e atitudes (SILVA; HOFF, 2015). 
As Secretarias de Educação têm um papel importante nessa formação, pois poderiam promover parcerias com universidades e faculdades para facilitar a busca por inovação e melhoria das práticas pedagógicas. Conhecendo as experiências de cada aluno e professor, respeitando as especificidades locais, possibilita a construção de uma melhor proposta pedagógica utilizando tais recursos (BITANTE et al., 2016). É necessário também que a gestão da instituição utilize estratégias de incentivo e formação junto aos professores, partindo da identificação dos problemas no contexto das tecnologias, de modo a permitir a construção ativa do conhecimento por parte do professor e do aluno, concretizando a cultura digital dentro da escola (COLETTO; BATTINI; MONTEIRO, 2018).

Silva, Neto e Azevedo (2018) investigaram as concepções de professores sobre as formações inicial e continuada quanto à sua influência na atividade docente e observaram em que prevalece uma concepção segregadora da formação docente, sendo a formação inicial e a formação continuada (tida como suplementar) distanciadas pela ideia de que estas são independentes também no aspecto cronológico. Considera-se que a formação inicial pode ser vista como suficiente para a preparação do profissional e provocar uma limitação da prática docente futura por acomodação ou falta de atualização.

Também foi notado que o uso da internet pelos professores se dá, principalmente, em casa, o que pode mostrar alguma fragilidade na oferta da rede de internet no ambiente escolar (Tabela 2). Segundo Silva e Hoff (2015), o uso das TIC deve estar articulado ao planejamento pedagógico escolar, através da organização, treinamento, controle e estabelecimento de cronogramas, com participação coletiva entre gestão, professores, alunos, pais e funcionários para que haja sucesso no uso das tecnologias em sala de aula. É preciso que o gestor crie um clima de confiança e compromisso junto ao professor, valorizando seu trabalho e viabilizando recursos humanos e materiais para maior consolidação dessas estratégias.

Os dados apontam que o computador foi utilizado pelos professores para diferentes fins, entre eles: as atividades diversas da sua disciplina (82\%); a elaboração de provas/relatórios (70\%) e para visitas a sites profissionais (70\%). Chama a atenção o uso do computador para pesquisa, que foi relatado por apenas $35 \%$ dos professores. Também foram referidos usos do computador para mandar e receber e-mails (41\%), ver notícias (24\%), participar de bate-papo $(12 \%)$ e jogos (12\%). Todos esses resultados são apresentados na Figura 1. 
Figura 1 - Distribuição das principais utilizações do computador pelos professores entrevistados (Petrolina, 2018)

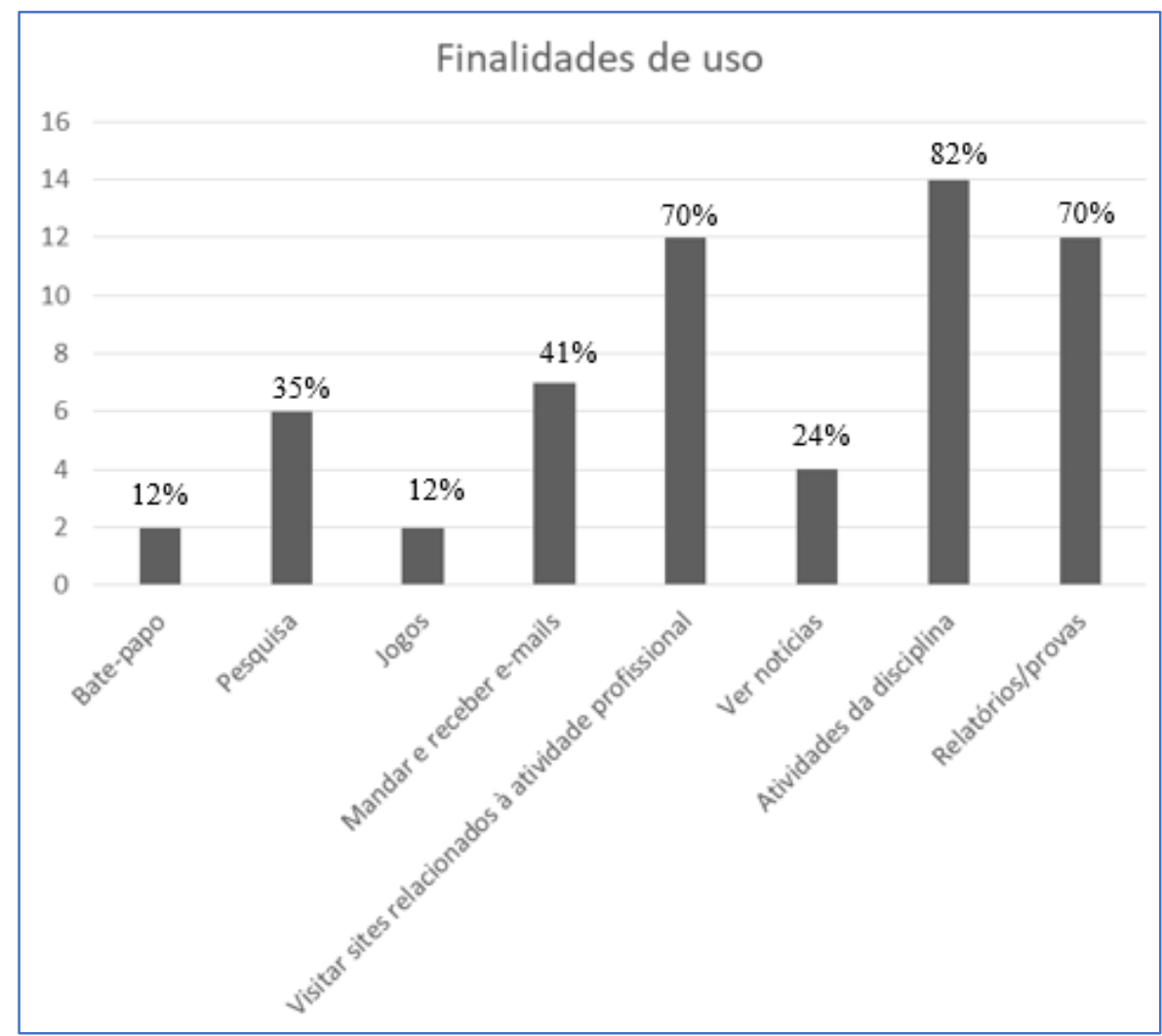

Fonte: Dados dos autores, 2018.

Em estudo de Bitante e colaboradores (2016) a utilização do computador pelos professores se deu em ações como o desenvolvimento de textos e desenhos, utilização da internet e divulgação dos trabalhos desenvolvidos pelos alunos, antes realizados de forma manual e com uma qualidade menor, mostrando assim que as TICs trouxeram melhorias para o aprendizado dos alunos. Porém, poucos tinham familiaridade em trabalhar com softwares, pois muitas vezes não receberam formação adequada, sendo muitas vezes autodidatas.

As opiniões dos professores relacionadas aos benefícios do uso do computador para fins didáticos, bem como a respeito da capacitação docente para a melhor utilização desse recurso, são apresentadas na Tabela 3. Ao analisar essa tabela, é verificado que a maioria dos professores concorda ser essencial que o docente receba alguma capacitação em informática para que possa utilizar essa ferramenta em atividades relacionadas à sua disciplina. Inclusive, a grande maioria deles afirma que essa formação deveria ser ofertada ainda no curso de graduação em Licenciatura (Tabela 3). 
Tabela 3 - Distribuição das opiniões dos professores abordados, com relação aos benefícios do uso do computador para fins didáticos e capacitação docente para o uso dessa ferramenta (Petrolina, 2018)

QUESTÕES

É essencial que o professor receba uma capacitação em informática para
que possa utilizar o computador em atividades pedagógicas de sua disciplina.

Discordo totalmente

Discordo parcialmente

Nem concordo nem discordo

Concordo parcialmente

Concordo Totalmente

Os cursos de Licenciatura precisam preparar os futuros professores para trabalhar com a informática em sala de aula.

Discordo totalmente

Discordo parcialmente

Nem concordo nem discordo

Concordo parcialmente

Concordo Totalmente

O computador contribui mais para o raciocínio e aprendizagem dos alunos que atividades convencionais de aula.

Discordo totalmente

Discordo parcialmente

Nem concordo nem discordo

Concordo parcialmente

Concordo Totalmente

O aluno tem maior motivação em realizar atividades de aula quando tem acesso ao computador na escola.

Discordo totalmente

Discordo parcialmente

Nem concordo nem discordo

Concordo parcialmente

Concordo Totalmente

O uso do computador, durante as aulas e fora dela, traz benefícios no rendimento dos alunos.

Discordo totalmente $\quad 1 \quad 6$

Discordo parcialmente $\quad 1 \quad 6$

Nem concordo nem discordo $\quad 2 \quad 12$

$\begin{array}{lll}\text { Concordo parcialmente } & 7 & 40\end{array}$

Concordo Totalmente $\quad 6 \quad 36$

O uso do computador na escola diminui a evasão escolar.

Discordo totalmente $\quad 5 \quad 28$

Discordo parcialmente $\quad 1 \quad 6$

Nem concordo nem discordo $\quad 6 \quad 36$

Concordo parcialmente $\quad 4 \quad 24$

Concordo Totalmente $\quad 1 \quad 6$

n= número de indivíduos; \%=porcentagem. Fonte: Dados dos autores, 2018.

Os professores também concordam que o uso do computador pode trazer benefícios no rendimento escolar dos alunos, contribui mais para o raciocínio e aprendizagem dos alunos que atividades convencionais de aula, bem como proporciona maior motivação ao aluno quando 
este utiliza o computador nas atividades de aula. Entretanto, as opiniões se dividem quanto à contribuição do uso desta ferramenta para a diminuição da evasão escolar (Tabela 3).

É importante salientar que cada professor procure a forma que mais lhe ajude na maneira de trabalhar com os alunos, facilitando sua comunicação, gerando melhores resultados para o aprendizado. A aprendizagem mediada pelas TICs só será eficaz, se professores e alunos atribuírem significados à enorme gama de informações recebidas diariamente, filtrando as mesmas e descartando aquelas que não agregam nenhum conhecimento (COLETTO; BATTINI; MONTEIRO, 2018).

No que se refere à percepção dos professores quanto à maior inserção do uso dessa ferramenta nas suas atividades de aula (Tabela 4), a maioria dos docentes concorda que deveria dispor mais tempo para utilizar o laboratório de informática com os alunos e inserir mais vezes essa ferramenta em suas aulas e também não considera que o uso do computador na disciplina comprometeria o cumprimento do cronograma de aulas. Apesar disso, grande parte dos professores acha que esse recurso ainda é limitado quando se pensa nos conteúdos que deveriam ser ministrados na disciplina. Outra informação importante é que metade dos professores considera que eles têm um papel fundamental na instrução dos alunos quanto ao uso do computador.

Tabela 4 - Distribuição das opiniões dos professores abordados, com relação ao uso do computador em suas disciplinas (Petrolina, 2018)

\begin{tabular}{lcc}
\hline \multicolumn{1}{c}{ QUESTÕES } & $\mathbf{n}$ & $\%$ \\
\hline $\begin{array}{l}\text { Devo dispor tempo, em minha carga horária, para ir com os alunos ao } \\
\text { laboratório de informática. }\end{array}$ & 0 & 0 \\
Discordo totalmente & 1 & 6 \\
Discordo parcialmente & 2 & 12 \\
Nem concordo nem discordo & 4 & 24 \\
Concordo parcialmente & 10 & 58 \\
Concordo Totalmente & & \\
Eu deveria utilizar mais o laboratório de informática em minhas aulas. & 0 \\
Discordo totalmente & 0 & 6 \\
Discordo parcialmente & 1 & 12 \\
Nem concordo nem discordo & 2 & 35 \\
Concordo parcialmente & 6 & 47 \\
Concordo Totalmente & 8 & 18 \\
O uso do computador é limitado quando se pensa nos conteúdos que & & 12 \\
precisam ser ministrados na disciplina. & & 3 \\
Discordo totalmente & 3 & 28 \\
Discordo parcialmente & 2 & 3 \\
Nem concordo nem discordo & 5 & 4 \\
Concordo parcialmente & & 24 \\
Concordo Totalmente & & \\
\hline
\end{tabular}




\begin{tabular}{lcc}
\hline $\begin{array}{l}\text { O professor é responsável pela instrução dos alunos quanto ao uso do } \\
\text { computador. }\end{array}$ & \\
Discordo totalmente & 2 & 12 \\
Discordo parcialmente & 3 & 17 \\
Nem concordo nem discordo & 2 & 12 \\
Concordo parcialmente & 6 & 35 \\
Concordo Totalmente & 4 & 24 \\
A utilização do computador durante o trabalho dos conteúdos das minhas & & \\
disciplinas atrapalha/atrapalharia o cumprimento do cronograma da & & \\
mesma. & 8 & 46 \\
Discordo totalmente & 4 & 24 \\
Discordo parcialmente & 2 & 12 \\
Nem concordo nem discordo & 2 & 12 \\
Concordo parcialmente & 1 & 6 \\
Concordo Totalmente & \\
\hline
\end{tabular}

n= número de indivíduos; \%=porcentagem. Fonte: Dados do autor, 2018.

Percebe-se, aí, um cenário contraditório, onde eles entendem que o ensino experimental por meio de um computador conectado à internet daria melhores condições de realizar atividades experimentais, muitas vezes impossibilitadas por falta de espaço físico e dificuldade de acesso aos experimentos. Porém, admitem que esses espaços ainda são pouco utilizados por eles, o que levanta a hipótese do desconhecimento dos professores quanto às suas reais potencialidades pedagógicas (Tabela 4).

É preciso ajustar a educação às novas realidades sociais, propondo outros ambientes de ensino que não seja focado no quadro-giz e no livro didático. A escola deve oferecer condições como laboratórios de informática com internet e cursos para os professores, fazendo com que o aluno rompa barreiras com o advento tecnológico disponível na atualidade. A internet é mais uma ferramenta para essa transformação social, uma vez que cria espaços para que haja discussões nos âmbitos mais diversos possíveis (PEREIRA; CHAGAS, 2014).

Para Kenski (2007) além do desconhecimento por parte dos professores com relação às potencialidades do uso das tecnologias para fins didáticos, também pode ocorrer uma não adequação da tecnologia ao conteúdo que vai ser ensinado ou aos objetivos da aula. Somados a essas dificuldades, aspectos relacionados à carreira do professor, como falta de tempo na jornada de trabalho e formação inicial precária, também justificam o fracasso na inserção das TIC na prática pedagógica docente. As dificuldades de implantação ou a falta de comprovação de sua eficácia não podem justificar o abandono do uso deste recurso e, sim, reforçam a necessidade de refinar e aperfeiçoar esses instrumentos (OLIVEIRA, 2006).

A análise dos resultados de uma pesquisa realizada com estudantes de Licenciatura em Biologia, onde foi trabalhado a inserção de recursos tecnológicos para fins pedagógicos, 
mostrou um bom envolvimento e comprometimento dos professores em formação com a proposta, mostrando melhorias no planejamento e no desenvolvimento das aulas de Biologia para o Ensino Médio, dentro da proposta colaborativa mediada pelo computador como recurso pedagógico, mostrando evidências de construção de saberes para a docência (GIANOTTO; DINIZ, 2010).

Diante do exposto, foi visto que a introdução das mídias e da tecnologia na prática educativa é um processo de mudança que envolve repensar o papel do professor para aprimorar o processo de ensino-aprendizagem, pois este é responsável por planejar, implementar e propor os métodos de ensino utilizando as TICs. Portanto, este docente deve ser ativo e responsável pelas mudanças em sua atuação, bem como ser o sujeito ativo dessa mudança (ROCHA, 2011). No presente estudo, os professores utilizam as tecnologias em suas práticas, porém sem modificar sua forma tradicional de ensino, fazendo com que esse recurso seja subutilizado, além de criar um comportamento de tensão e resistência na figura do professor, por não conhecer o real potencial pedagógico do mesmo em suas disciplinas.

\section{CONSIDERAÇÕES FinAIS}

É fato que os computadores estão presentes nas escolas, mesmo que os laboratórios de informática não têm sido utilizados em toda sua potencialidade, mas este artigo mostra as contradições existentes na inserção das TICs nas escolas estudadas, no caso deste estudo, o computador. Foi visto que a grande maioria dos docentes afirma fazer uso do computador em sua prática docente, apesar das extensas jornadas de trabalho apresentadas por esses indivíduos.

No entanto, não parece claro para eles o que seria o uso desta tecnologia, uma vez que voltam a afirmar que este recurso é considerado limitado para a abordagem dos conteúdos de suas disciplinas e admitem que deveriam dispor de mais tempo para uso dos recursos, bem como explorar melhor os laboratórios de informática da escola.

Por isso, não basta apenas inserir as tecnologias nas escolas, é imprescindível discutir melhor seu uso, investigar quais aspectos são relevantes para que o professor se sinta seguro em utilizar mais essa ferramenta, bem como avaliar quais as reais mudanças pedagógicas da prática docente após a inserção deste recurso. O que foi bastante positivo nos dados obtidos, é perceber que o corpo docente acredita no potencial das TICs na melhoria da aprendizagem e no rendimento dos alunos, mostrando que este recurso não é rejeitado pelos professores, no entanto, precisa de um maior investimento em sua formação e maior incentivo por parte da gestão escolar enquanto política pública educacional. 


\section{REFERÊNCIAS}

ANJOS, Letícia Fernanda Rodrigues; OLIVEIRA, Maria Eduarda Peres; CAIXETA, Juliana Eugênia. A percepção de professores sobre o uso das tecnologias de Informação e de comunicação - TIC's no processo de ensino. Anais eletrônicos do I Simpósio Regional de Educação, 2014. Disponível em: http://geces.com.br/simposio/anais/wpcontent/uploads/2014/04/PERCEPCAO_DE_PROFESSORES.pdf. Acesso em: 09/05/2017.

ARANCIBIA HERRERA, Marcelo Maurício; CASANOVA SEGUEL, Roberto; SOTO CARO, Carmem Paz. Concepciones de profesores sobre aprender y enseñar usando tecnologías. Ciencia, Docencia y Tecnología, v.27, n.52, p.106-126, mayo, 2016.

BARBOSA, Maria Lúcia Marangon. Utilizando o computador como ferramenta pedagógica para vencer a resistência do professor - o caso da $38^{\mathrm{a}}$ Superintendência Regional de Ensino de Ubá - MG. Dissertação de mestrado, 2002, 104p.

BITANTE Alessandra Preto; FARIA, Ana Cristina; GASPAR, Marcos Antonio; PASCUAL José Valentin Iglesias; DONAIRE, Denis. Impactos da tecnologia da informação e comunicação na aprendizagem dos alunos em escolas públicas de São Caetano do Sul (SP). HOLOS, Ano 32, v. 08, p.281-302, 2016.

CETIC.BR. Centro Regional de Estudos para o Desenvolvimento da Sociedade da Informação. Educação e tecnologias no Brasil [livro eletrônico]: um estudo de caso longitudinal sobre o uso das tecnologias de informação e comunicação em 12 escolas públicas. 1. ed. São Paulo: Comitê Gestor da Internet no Brasil, 2016. Disponível em: https://cetic.br/publicacao/educacao-e-tecnologias-no-brasil/. Acesso em: 17 ago. 2017.

COLETTO, Priscila Miranda de Carvalho; BATTINI, Okçana; MONTEIRO, Edenar. Tecnologias da informação e comunicação e as metodologias ativas: elementos para o trabalho docente no ensino superior. Revista Prática Docente. v. 3, n. 2, p. 798-812, jul/dez 2018.

GIANOTTO, Dulcinéia Ester Pagani; DINIZ, Renato Eugênio da Silva. Formação inicial de professores de biologia: a metodologia colaborativa mediada pelo computador e a aprendizagem para a docência. Ciência \& Educação, v. 16, n. 3, p. 631-648, 2010.

NISHI, Juliana Mayumi; SILINSKE, Jaqueline; LÖBLER, Mauri Leodir. O uso pedagógico das TICS: As percepções dos docentes diante suas competências tecnológicas. Revista Espacios. v.38, n.15, p.10-24, 2017.

OLIVEIRA, Liliane Silva Câmara; BENDITO, Dennefe Vicencia; SANTOS, Nivia Maria Rodrigues; LUNA, Karla Patricia de Oliveira. Apresentação metodológica com uso de tecnologia digital no ensino de ciências. Revista SUSTINERE, Rio de Janeiro, v. 5, n. 1, p. 68-89, jan-jun, 2017.

OLIVEIRA, José Augusto. Escrevendo com o computador na sala de aula. 1 ed. São Paulo: Cortez, 2006, 115p.

ORTEGA, Patricia Raquimán. Representaciones sobre el cambio en el uso de las TIC: Relatos de vida de professores. Revista Iberoamericana de Educación. n. 65, p.75-90, 2014. 
PEREIRA, Stelamara Souza; CHAGAS, Flomar Ambrosina Oliveira. Tecnologia e educação: uma conexão no ensino da matemática. Estudos, Goiânia, v. 41, n. 1, p. 140-150, jan./mar. 2014.

ROCHA, Termisia Luiza. Percepção do professor acerca do uso das mídias e da tecnologia na prática pedagógica. Cadernos da FUCAMP, v.10, n.13, p.1-10, 2011.

SCHUHMACHER Vera Rejane Niedersberg; ALVES FILHO, José de Pinho; SCHUHMACHER, Elcio. As barreiras da prática docente no uso das tecnologias de informação e comunicação. Ciênc. Educ., Bauru, v. 23, n. 3, p. 563-576, 2017.

SILVA, Monalisa Pivetta; HOFF, Rafael. Formação docente e as TICS: percepção de professores do meio-oeste de Santa Catarina - Brasil. Unoesc \& Ciência - ACHS Joaçaba, v. 6, n. 2, p. 165-172, jul./dez. 2015.

SILVA, Flávia Beatriz de Oliveira; NETO, Luiz Sodré; AZEVEDO, Thamara de Medeiros. Concepções de professores sobre formação docente para a prática de ensino de ciências. Revista Prática Docente. v. 3, n. 2, p. 506-518, jul/dez 2018.

Recebido em: 09 de abril de 2019. Aprovado em: 16 de dezembro de 2019. 